\title{
3 Research Square

\section{Oral etoposide and trastuzumab in HER2-positive metastatic breast cancer: a retrospective study at Institut Curie Hospitals.}

Florence Lerebours ( $\sim$ florence.lerebours@curie.fr)

Department of Medical Oncology, Institut Curie, Paris and St Cloud

Clelia Chalumeau

Department of Medical Oncology, Institut Curie, Paris and St Cloud

Matthieu Carton

Biostatistics, Institut Curie, Paris

Alexandre Eeckhoutte

DNA Repair and Uveal Melanoma (D.R.U.M.), Inserm U830, Institut Curie, Paris 75248

Stelly Ballet

Department of Diagnostic and Theranostic Medicine, Institut Curie, Paris

Anne Vincent-Salomon

Department of Diagnostic and Theranostic Medicine, Institut Curie, Paris

\section{Perrine Vuagnat}

Department of Medical Oncology, Institut Curie, Paris and St Cloud

\section{Audrey Bellesoeur}

Department of Medical Oncology, Institut Curie, Paris and St Cloud

Jean-Yves Pierga

Department of Medical Oncology, Institut Curie, Paris and St Cloud

Marc-Henri Stern

DNA Repair and Uveal Melanoma (D.R.U.M.), Inserm U830, Institut Curie, Paris 75248

Francois-Clement Bidard

Department of Medical Oncology, Institut Curie, Paris and St Cloud

\section{Research Article}

Keywords: HER2 metastatic breast cancer, oral etoposide, trastuzumab, TOP2A/ERBB2 co-amplification

Posted Date: February 17th, 2022

DOI: https://doi.org/10.21203/rs.3.rs-1325343/v1 
License: (c) (i) This work is licensed under a Creative Commons Attribution 4.0 International License. Read Full License 


\section{Abstract}

Background: The TOP2A and ERBB2 genes are co-amplified in about 40\% of HER2 positive (HER2+) breast cancers. Oral etoposide (VP16), an inhibitor of topoisomerase-ll (encoded by TOP2A), has demonstrated clinical activity in metastatic breast cancer (MBC). However, the clinical benefit of oral VP16 combined with trastuzumab (VP16-T) in HER2+ MBC has not been evaluated.

Methods: Patients treated at Institut Curie Hospitals with VP16-T for HER2+ MBC were retrieved by an insilico search. Trained medical oncologists retrospectively assessed progression-free survival (PFS), overall survival (OS), response rate, prolonged PFS (defined as a duration of at least 6 months), 6 months clinical benefit rate and toxicity. Co-amplification of ERBB2 and TOP2A was assessed by shallow whole genome sequencing on tumor tissue whenever available.

Results: Forty-three patients received VP16-T after a median number of six prior treatment lines for HER2+ MBC. Median PFS and OS were 2.9 months (95\% Cl [2.4-4.7]) and 11.3 months (95\% Cl [8.3-25.0]), respectively. Three patients had a complete response while 12/40 (30\%) had a clinical benefit. Only 3 patients stopped treatment for toxicity. Median PFS in the population with and without TOP2A/ERBB2 coamplification was respectively 4.7 months ( $95 \% \mathrm{Cl}$ [2.3-NA]) and 2.9 months ( $95 \% \mathrm{Cl}$ [1.2-NA]; $\mathrm{p}=0.36)$.

Conclusion: Our analysis suggests a favorable efficacy and toxicity profile for VP16-T in patients with heavily pretreated HER2+ MBC.

\section{Background}

Approximately $15 \%$ of breast cancers display an amplification of ERBB2, which is encoding the human epidermal growth factor receptor 2 (HER2) and is associated with poorer prognosis (1-3). HER2-targeted cancer therapies such as trastuzumab, pertuzumab, trastuzumab emtansine (T-DM1), lapatinib and newer therapies (such as trastuzumab deruxtecan and tucatinib) have significantly improved the outcome of HER2 + metastatic breast cancer (HER2 + MBC) patients (4-9). Current treatment guidelines support the maintenance of anti-HER2 therapy throughout the different lines of treatment $(10,11)$.

Oral etoposide (VP16) is an inhibitor of topoisomerase II. Oral VP16 has demonstrated clinical activity in heavily pre-treated patients with HER2-negative MBC compared to other active chemotherapies such as capecitabine, paclitaxel, eribulin or anthracyclines (17). Although not currently recommended in MBC guidelines, the use of oral VP16 could be relevant in heavily pre-treated MBC, with the advantage of an oral administration, a low cost and manageable toxicity. Moreover, while the cardiac toxicity of anthracyclins is overlapping that of anti-HER2 targeted agents (12), oral VP16 has no reported cardiac toxicity, thus allowing combination therapy.

TOP2A, the gene encoding topoisomerase II, is located on the long arm of chromosome 17 (17q21-22), close to ERBB2 (18). It has been reported that up to $40 \%$ of HER2 + breast cancers display a co- 
amplification of TOP2A and ERBB2 genes (19), which has been investigated as a predictive marker of anthracycline efficacy (19-23) in HER2 + breast cancers, with controversial results (24-27).

To the best of our knowledge, there are no studies evaluating the efficacy of oral VP16 in combination with trastuzumab, a combination used in our institute as a palliative, late line therapy for HER2 + MBC patients. Here, we report a retrospective evaluation of the efficacy and safety of oral VP16 combined with trastuzumab in HER2 + MBC and the predictive value of TOP2A/ERBB2 co-amplification.

\section{Methods}

\section{Patients and clinical data}

The research project was submitted and approved by the Internal Research Committee of the Institut Curie (No. DATA200187). A waiver of informed consent was obtained because of the retrospective nature of the study.

Patients treated with oral VP16 and trastuzumab were retrieved by an in-silico search in the database of Institut Curie Hospitals (Paris and Saint Cloud, France). Computerized medical files were then manually inspected by experienced medical oncologists. Inclusion criteria were: HER2 + MBC female patients treated with oral VP16 in combination with trastuzumab, regardless of the treatment line. HER2 + tumors were defined according to the 2018 American Society of Clinical Oncology/College of American Pathologists guidelines (3). Trastuzumab could have been received prior to oral VP16 and continued after VP16-T treatment. All oral VP16 administration regimens were included in the study. The dose of 50mg or 75mg per day for 10-14 days out of 21 was defined as the standard oral VP16 regimen (28).

The primary objective was to evaluate the progression-free survival (PFS) in HER2 + MBC patients treated by VP16-T. PFS was defined as the period from initiation of combination therapy to disease progression or death for any cause, whichever came first.

Secondary objectives were to evaluate overall survival (OS), progression-free survival (PFS) under the prior treatment line, response rate, clinical benefit, toxicity and predictive value of TOP2/ERBB2 coamplification. OS was calculated from the start of treatment until death from any cause or until the last date the patient was known to be alive. The response rate was measured as the ratio between patients experiencing a partial or complete response as best response, using RECIST 1.1 criteria, and patients who had a measurable disease at treatment start (29). Clinical benefit at 24 weeks was defined as a PFS > 24 weeks and/or objective tumor response. Toxicities were retrospectively classified according to the National Cancer Institute's Common Criteria for Toxicity (version 5.0).

\section{TOP2A/ERBB2 co-amplification}

TOP2A/ERBB2 co-amplification was analyzed by shallow Whole Genome Sequencing (sWGS) using Formalin-Fixed Paraffin-Embedded (FFPE) tumor tissue (30-32) from an available tumor tissue (from metastasis or primary tumor). All slides have been reviewed by a pathologist, to ensure a minimum tumor 
cellularity of $30 \%$. Between 5 and $50 \mathrm{ng}$ (when available) of tumor DNA were processed with the precapture kit XT-HS2 (Agilent) according to the manufacturing protocol. First, DNAs were fragmented with the ME220 sonicator, reparated, adenylated and ligated with the duplex molecular barcode and the Illumina paired-end sequencing elements during $1 \mathrm{~h}$. Then, unique dual sample indexes were added by 14 cycles of PCR amplification. The libraries were qualified and quantified by the HS Qubit kit and TapeStation 4200 (Agilent) with the D1000 DNA ScreenTape analysis kit prior to pooling in one single tube. The final pool was finally quantified by qPCR on the 7500 Real-Time PCR System (Thermo Fisher Scientific). $100 \mathrm{pb}$ paired-end shallow sequencing was performed at Institut Curie core sequencing facility, using an Illumina Novaseq6000.

Sequencing files were pre-processed as indicated in Eeckhoutte et al, 2020 (33). Details are available upon request. Pre-processed alignment files were analyzed by counting and normalizing the number of aligned reads in fixed window of $50 \mathrm{~kb}$ with QDNAseq (34).QDNAseq associates contiguous windows considered to be in the same copy number level in genomic segments. The middle of TOP2A and ERBB2 loci were used to extract from QDNAseq their respective fixed window and genomic segment values. QDNAseq outputs were then processed with shallowHRD (33), which extracts a minimal copy number alteration (CNA) cut-off.

The TOP2A/ERBB2 co-amplification status was defined when associated fixed window and segment values of both genes were over 4-fold of the CNA cut-off. The absence of TOP2A/ERBB2 co-amplification status was defined when the fixed window and segment values of ERBB2 were over 4-fold of the CNA cutoff and those of TOP2A less than 4-fold of the CNA cut-off. Samples were classified as "not interpretable" in case of discrepancy between window and segment values for one gene or if no amplification of ERBB2 was retrieved by sWGS.

\section{Statistics}

Quantitative variables are presented with their median, minimum and maximum. Qualitative variables are presented with the number and percentage. Missing data (not available $=$ NA) are excluded from the denominator for the calculation of percentages. Median follow-up was determined by the inverted Kaplan-Meier method (35). Median values for PFS and OS (with their $95 \%$ confidence intervals [CI]) were estimated using the Kaplan-Meier method. All statistical analyses were performed using R 3.6 (36).

\section{Results}

\section{Patients and treatment}

2,003 patients treated for HER2+ MBC were retrieved by in silico screening of the Institut Curie electronic medical files. Among those patients, 43 met inclusion criteria and were analyzed as part of this retrospective study: their characteristics are shown in Table 1. The median age at diagnosis of primary breast cancer was 47 years (22-80 years). The median age at diagnosis of MBC was 51 years (22-83 years). Synchronous BC metastases were diagnosed in 14 (33\%) patients (de novo stage IV). Patients 
had received a median number of six prior treatment lines (range 0-12) at the time of receiving VP16-T regimen. Thirty-five patients $(81 \%)$ had visceral metastases. Oral VP16 regimen was administered at the above-defined standard doses to 31 patients (72\%). Median duration of VP16-T treatment was 2.9 months ( 0.2 - 14.6 months). VP16-T was stopped for disease-progression ( $n=35$ patients, $81 \%$ ), toxicity $(n=3$ patients, $7 \%)$, therapeutic break ( $n=3$ patients, $7 \%$ ) or unknown cause $(n=2$ patients, $5 \%)$.

\section{Table 1}

Patients' characteristics 


\begin{tabular}{|c|c|c|c|}
\hline & & $\mathrm{N}$ patients & $\%$ \\
\hline \multirow[t]{3}{*}{ Phenotype } & HER2+ & 43 & 100 \\
\hline & HER2+/HR+ & 21 & 49 \\
\hline & HER2+/HR- & 22 & 51 \\
\hline Age at primary $B C$ & $<50$ & 27 & 63 \\
\hline (Years) & $\geq 50$ & 16 & 37 \\
\hline Age at metastatic BC & $<50$ & 21 & 49 \\
\hline (Years) & $\geq 50$ & 22 & 51 \\
\hline \multirow[t]{5}{*}{ Stage at $\mathrm{BC}$ diagnosis } & 0 & 1 & 2 \\
\hline & I & 5 & 12 \\
\hline & II & 10 & 23 \\
\hline & III & 13 & 30 \\
\hline & IV & 14 & 33 \\
\hline \multirow[t]{2}{*}{ Histological type } & Ductal & 38 & 88 \\
\hline & Lobular & 5 & 12 \\
\hline \multirow[t]{3}{*}{ Histological grade (EE) } & 1 & 3 & 7 \\
\hline & 2 & 19 & 44 \\
\hline & 3 & 21 & 49 \\
\hline \multirow[t]{4}{*}{ Metastasis-Free Interval } & de novo & 14 & 33 \\
\hline & [6-24] months & 6 & 14 \\
\hline & ]24-60] months & 14 & 33 \\
\hline & $>60$ months & 9 & 20 \\
\hline \multirow[t]{2}{*}{ Number of metastatic sites } & $\leq 2$ & 12 & 28 \\
\hline & $>2$ & 31 & 72 \\
\hline \multirow[t]{2}{*}{ Visceral metastases } & No & 8 & 19 \\
\hline & Yes & 35 & 81 \\
\hline \multirow[t]{4}{*}{ Number of prior treatment lines } & $<2$ & 3 & 7 \\
\hline & 3 & 6 & 14 \\
\hline & 4 & 8 & 19 \\
\hline & 5 & 4 & 9 \\
\hline
\end{tabular}


Brain metastases were observed in 22 of 40 evaluable patients and in 6 of 12 patients with prolonged PFS. Among these 6 patients with brain metastases and prolonged PFS, only one experienced a disease progression of her brain metastases while receiving VP16-T.

\section{Toxicity}

Toxicity has been retrospectively assessed for 42 patients (Table 2). Oral VP16 was discontinued due to toxicity in 3 patients: two for grade 3 nausea/vomiting, one for febrile neutropenia. Nauseas (grade 2 and 3) were observed in $14 \%$ of cases. Grade 1 alopecia was recorded in only 1 patient. No diarrhea, mucositis or allergies were observed.

\section{Table 2}

Toxicities

\begin{tabular}{|llll|}
\hline Toxicity & $\begin{array}{l}\text { Grade 1 } \\
\mathrm{N}(\%)\end{array}$ & $\begin{array}{l}\text { Grade 2 } \\
\mathrm{N}(\%)\end{array}$ & $\begin{array}{l}\text { Grade 3 } \\
\mathrm{N}(\%)\end{array}$ \\
\hline Nausea & 0 & $4(10)$ & $2(5)$ \\
\hline Neutropenia & $3(7)$ & $1(2)$ & $1(2)$ \\
\hline Alopecia & $1(2)$ & 0 & 0 \\
\hline Asthenia & $17(40)$ & $10(24)$ & $8(19)$ \\
\hline
\end{tabular}

\section{TOP2AVERBB2 co-amplification}

FFPE tumor samples were available for DNA extraction for 23 patients. sWGS was not interpretable for 3 samples. Among the 20 patients included in sWGS analysis, seven (35\%) displayed an TOP2A/ERBB2 coamplification (examples are shown in Suppl file 3). Three patients with TOP2A/ERBB2 co-amplification had a clinical benefit at 24 weeks (including 2 patients with complete response). The median PFS was 3.4 months (95\% $\mathrm{Cl}$ [2.3-6.9]) in these 20 cases, which is comparable to the overall study population (2.9 months, $95 \% \mathrm{Cl}[2.4-4.7])$.

No statistically significant correlation was found between outcome and TOP2A/ERBB2 co-amplification: median PFS in the population with and without TOP2A/ERBB2 co-amplification was respectively 4.7 months (95\% Cl [2.3-NA]) and 2.9 months (95\% Cl [1.2-NA]; $\mathrm{p}=0.36)$ (Figure 3). Three (43\%) patients with clinical benefit had TOP2A/ERBB2 co-amplification and four (31\%) patients without clinical benefit had TOP2A/ERBB2 co-amplification (Fisher $\mathrm{p}=0.65$ ). 


\section{Discussion}

To our knowledge, no studies have evaluated the efficacy of oral VP16 and trastuzumab combination in HER2 + MBC. We show that this combination achieves clinically meaningful PFS with about one third of prolonged PFS (defined as PFS greater than or equal to 6 months), a clinical benefit in a third of patients, and 3 complete responses. PFS and OS were 2.9 months and 11.3 months, respectively. These results were obtained in a heavily pre-treated population with a median number of six prior treatment lines for MBC. Moreover, most of our patient population displayed unfavorable clinical features, such as visceral metastases. Limitations of our study are related to its limited size and retrospective nature. However, this study is the first specifically analyzing outcome and toxicity of oral VP16 associated with trastuzumab for HER2 + MBC.

Oral VP16 is a metronomic chemotherapy, defined as the regular administration of a minimally toxic dose of treatment over an extended period of time. In advanced breast cancer, metronomic chemotherapy has been shown to provide disease control with a lower incidence of adverse events compared to conventional chemotherapy at the maximum tolerated dose $(37,38)$. In the years 1994 to 2000 , oral VP16 showed interesting clinical activity in patients with MBC after multiple lines of treatment (39-43). More recently, a study by Cabel et al. (17) showed survival rates with oral VP16 comparable to other treatment lines including capecitabine, paclitaxel, eribulin or anthracycline (median PFS of 3.2 months) in patients with HER2-negative MBC.

Some studies reported the outcome of HER2 + MBC treated with oral VP16. In 2015, a retrospective study by Valaberga et al. (44) found a 4 months median PFS with oral VP16 in patients who received a median of 8 treatment lines (range 2-13). Twenty-one patients out of 66 had HER2 + MBC. The PFS did not differ between HER2-positive and HER2-negative status. Another retrospective study (45) included 110 pretreated patients with a median of 5 lines of treatment. Twenty-five of these patients had HER2 + MBC. The median duration of treatment was 4 months with, again, no significant difference according to HER2 status. In a prospective phase II study (46), a median PFS of 4.5 months as reported in 75 patients with MBC and a median number of 2 prior lines of therapy, of which 22 had an HER2 + disease. A review of twelve studies, including about a third of HER2 + MBC patients, reported an overall $18.5 \%$ response rate with oral VP16 (47). None of these studies specified the use of anti-HER2 therapy in combination with oral VP16. The low number of HER2 + MBC in these studies and the lack of specific subgroup analysis prevent any further comparison with our results.

There is limited data available on the efficacy of other late line chemotherapies and trastuzumab in pretreated HER2 + MBC. The efficacy of vinorelbine and trastuzumab was assessed in two prospective studies. In 46 patients treated with vinorelbine in a second-line setting after progression on a first-line taxane-based regimen, Blancas et al. (52) reported a 7 months median PFS in seven HER2 + MBC patients. The phase II study of Lee et al. (53) showed a median PFS of 6.8 months in 33 HER2 + MBC patients with HER2 $+\mathrm{MBC}$ and a median of four prior lines of systemic treatment. Gemcitabine and trastuzumab has been investigated in two studies: Bartsch et al. (48) and Yardley et al. (49) included 23 
and 37 patients respectively. These studies included patients who received a median of two prior lines of systemic therapy for HER2 + MBC and reported a median PFS of 3 and 4 months respectively. PFS of similar ranges were observed in the control arm of the TH3RESA trial (6). In this pivotal trial, 602 HER2 + MBC patients who received a median of four prior lines of therapy demonstrated a significantly improved median PFS with trastuzumab-emtansine compared with physician-selected therapy (6.2 months versus 3.3 months). In the treatment of physician's choice arm, $68 \%$ of patient received concomitant trastuzumab and chemotherapy (vinorelbine in $32 \%$ of patients, gemcitabine in $16 \%$ of patients). Interestingly, the median PFS in the control arm of TH3RESA is similar to that observed with VP16 and trastuzumab in our report.

Presence of a co-amplification of TOP2A and ERBB2 on chromosome 17 suggests a biological interest to combine oral VP16 and trastuzumab in HER2 + MBC. In keeping with prior reports, our sWGS analysis retrieved a TOP2A/ERBB2 co-amplification in 35\% of cases. TOP2A/ERBB2 co-amplification was numerically, but not statistically, more frequent in patients benefiting from VP16-T. The limited number of patients analyzed prevents any definitive conclusion about the predictive value of the co-amplification. Of note, other non-genetic mechanisms may also modulate the response to topoisomerase 2 inhibitors (20), such as epigenetic mechanisms modulating DNA accessibility (58).

\section{Conclusions}

Finally, our retrospective study suggests oral VP16 and trastuzumab may be considered as a treatment option in heavily pre-treated HER2 + MBC patients. This combination yields to prolonged responses in some patients and has the advantage of an oral administration, limited cost and acceptable toxicity.

\section{Abbreviations}

CNA: Copy Number Alteration

DNA: DeoxyriboNucleic Acid

EE: Elston and Ellis

FFPE: Formalin-Fixed Paraffin-Embedded

HER2: Human Epidermal growth Factor Receptor 2

HR: Hormone Receptor

MBC: Metastatic Breast Cancer

OS: Overall Survival

PCR: Polymerase Chain Reaction 
PFS: Progression-Free Survival

QDNAseq: Quantitative DNA Sequencing

qPCR: quatitative Polymerase Chain Reaction

shallowHRD: shallow Homologous Recombination Deficiency

sWGS: shallow Whole Genome Sequencing

VP16: Oral etoposide

VP16-T: VP16 combined with trastuzumab

\section{Declarations}

\section{- Ethical Approval and Consent to participate:}

The research project was approved by the Internal Research Committee of the Institut Curie (No. DATA200187). A waiver of informed consent was obtained because of the retrospective nature of the study.

\section{- Consent for publication:}

Not applicable.

\section{- Availability of supporting data:}

The datasets used and analyzed during this study are available upon request from the corresponding author.

\section{- Competing interests:}

The author declared no conflict of interest.

\section{- Funding:}

This research received no specific grant from any funding agency in the public, commercial, or not-forprofit sectors. 


\section{- Authors' contributions:}

CC, MC, FCB and FL made substantial contributions to conception and design, and revising the manuscript, and gave final approval for publication. CC, MC, AE, SB, MHS, FCB and FL contributed to acquisition of data, analysis and interpretation of data. $C C, M C, A E, F C B$ and FL drafted the manuscript. CC, MC, and AE performed data analysis for the study. CC, MC, FCB and FL participated in manuscript preparation and revision. All other authors made substantial contributions to the acquisition of data, revising the manuscript, and final approval.

\section{- Acknowledgements:}

Not applicable.

\section{References}

1. Ross JS, Slodkowska EA, Symmans WF, Pusztai L, Ravdin PM, Hortobagyi GN. The HER-2 receptor and breast cancer: ten years of targeted anti-HER-2 therapy and personalized medicine. The Oncologist. avr 2009;14(4):320-68.

2. Slamon DJ, Clark GM, Wong SG, Levin WJ, Ullrich A, McGuire WL. Human breast cancer: correlation of relapse and survival with amplification of the HER-2/neu oncogene. Science. 9 janv 1987;235(4785):177-82.

3. Wolff AC, Hammond MEH, Allison KH, Harvey BE, Mangu PB, Bartlett JMS, et al. Human Epidermal Growth Factor Receptor 2 Testing in Breast Cancer: American Society of Clinical Oncology/College of American Pathologists Clinical Practice Guideline Focused Update. J Clin Oncol Off J Am Soc Clin Oncol. 10 2018;36(20):2105-22.

4. Baselga J, Cortés J, Kim S-B, Im S-A, Hegg R, Im Y-H, et al. Pertuzumab plus trastuzumab plus docetaxel for metastatic breast cancer. N Engl J Med. 12 janv 2012;366(2):109-19.

5. Geyer CE, Forster J, Lindquist D, Chan S, Romieu CG, Pienkowski T, et al.Lapatinib plus capecitabine for HER2-positive advanced breast cancer. N Engl J Med. 28 déc 2006;355(26):2733-43.

6. Krop IE, Kim S-B, González-Martín A, LoRusso PM, Ferrero J-M, Smitt M, et al. Trastuzumab emtansine versus treatment of physician's choice for pretreated HER2-positive advanced breast cancer (TH3RESA): a randomised, open-label, phase 3 trial. Lancet Oncol. juin 2014;15(7):689-99.

7. Cameron D, Casey M, Oliva C, Newstat B, Imwalle B, Geyer CE. Lapatinib plus capecitabine in women with HER-2-positive advanced breast cancer: final survival analysis of a phase III randomized trial. The Oncologist. 2010;15(9):924-34.

8. Verma S, Miles D, Gianni L, Krop IE, Welslau M, Baselga J, et al. Trastuzumab emtansine for HER2positive advanced breast cancer. N Engl J Med. 8 nov 2012;367(19):1783-91.

9. Swain SM, Baselga J, Kim S-B, Ro J, Semiglazov V, Campone M, et al. Pertuzumab, trastuzumab, and docetaxel in HER2-positive metastatic breast cancer. N Engl J Med. 19 févr 2015;372(8):724-34. 
10. von Minckwitz G, Schwedler K, Schmidt M, Barinoff J, Mundhenke C, Cufer T, et al. Trastuzumab beyond progression: overall survival analysis of the GBG 26/BIG 3-05 phase III study in HER2positive breast cancer.Eur J Cancer Oxf Engl 1990. oct 2011;47(15):2273-81.

11. von Minckwitz G, du Bois A, Schmidt M, Maass N, Cufer T, de Jongh FE, et al.Trastuzumab beyond progression in human epidermal growth factor receptor 2-positive advanced breast cancer: a german breast group 26/breast international group 03-05 study. J Clin Oncol Off J Am Soc Clin Oncol. 20 avr 2009;27(12):1999-2006.

12. Slamon DJ, Leyland-Jones B, Shak S, Fuchs H, Paton V, Bajamonde A, et al. Use of chemotherapy plus a monoclonal antibody against HER2 for metastatic breast cancer that overexpresses HER2. N Engl J Med. 15 mars 2001;344(11):783-92.

13. Schneeweiss A, Chia S, Hickish T, Harvey V, Eniu A, Hegg R, et al. Pertuzumab plus trastuzumab in combination with standard neoadjuvant anthracycline-containing and anthracycline-free chemotherapy regimens in patients with HER2-positive early breast cancer: a randomized phase II cardiac safety study (TRYPHAENA). Ann Oncol Off J Eur Soc Med Oncol. sept 2013;24(9):2278-84.

14. Slamon D, Eiermann W, Robert N, Pienkowski T, Martin M, Press M, et al. Adjuvant trastuzumab in HER2-positive breast cancer. N Engl J Med. 6 oct 2011;365(14):1273-83.

15. Montemurro F, Rossi V, Nolè F, Redana S, Donadio M, Martinello R, et al. Underuse of anthracyclines in women with HER-2+ advanced breast cancer. The Oncologist. 2010;15(7):665-72.

16. Giordano SH, Lin Y-L, Kuo YF, Hortobagyi GN, Goodwin JS. Decline in the use of anthracyclines for breast cancer. J Clin Oncol Off J Am Soc Clin Oncol. 20 juin 2012;30(18):2232-9.

17. Cabel L, Carton M, Cheaib B, Pierga J-Y, Dalenc F, Mailliez A, et al.Oral etoposide in heavily pre-treated metastatic breast cancer: results from the ESME cohort and comparison with other chemotherapy regimens. Breast Cancer Res Treat. janv 2019;173(2):397-406.

18. Press MF, Sauter G, Buyse M, Bernstein L, Guzman R, Santiago A, et al. Alteration of topoisomerase IIalpha gene in human breast cancer: association with responsiveness to anthracycline-based chemotherapy. J Clin Oncol Off J Am Soc Clin Oncol. 1 mars 2011;29(7):859-67.

19. Heestand GM, Schwaederle M, Gatalica Z, Arguello D, Kurzrock R. Topoisomerase expression and amplification in solid tumours: Analysis of 24,262 patients. Eur J Cancer Oxf Engl 1990. sept 2017;83:80-7.

20. Di Leo A, Desmedt C, Bartlett JMS, Piette F, Ejlertsen B, Pritchard KI, et al. HER2 and TOP2A as predictive markers for anthracycline-containing chemotherapy regimens as adjuvant treatment of breast cancer: a meta-analysis of individual patient data. Lancet Oncol. nov 2011;12(12):1134-42.

21. O'Malley FP, Chia S, Tu D, Shepherd LE, Levine MN, Bramwell VH, et al. Topoisomerase II alpha and responsiveness of breast cancer to adjuvant chemotherapy. J Natl Cancer Inst. 6 mai 2009;101(9):644-50.

22. Almeida D, Gerhard R, Leitão D, Davilla C, Damasceno M, Schmitt F. Topoisomerase II-alfa gene as a predictive marker of response to anthracyclines in breast cancer. Pathol - Res Pract. 1 oct 2014;210(10):675-9. 
23. Scandinavian Breast Group Trial 9401, Tanner M, Isola J, Wiklund T, Erikstein B, Kellokumpu-Lehtinen $\mathrm{P}$, et al. Topoisomerase llalpha gene amplification predicts favorable treatment response to tailored and dose-escalated anthracycline-based adjuvant chemotherapy in HER-2/neu-amplified breast cancer: Scandinavian Breast Group Trial 9401. J Clin Oncol Off J Am Soc Clin Oncol. 1 juin 2006;24(16):2428-36.

24. Fountzilas G, Dafni U, Bobos M, Kotoula V, Batistatou A, Xanthakis I, et al. Evaluation of the prognostic role of centromere 17 gain and HER2/topoisomerase II alpha gene status and protein expression in patients with breast cancer treated with anthracycline-containing adjuvant chemotherapy: pooled analysis of two Hellenic Cooperative Oncology Group (HeCOG) phase III trials. BMC Cancer. 28 mars 2013;13:163.

25. Tubbs R, Barlow WE, Budd GT, Swain E, Porter P, Gown A, et al. Outcome of patients with early-stage breast cancer treated with doxorubicin-based adjuvant chemotherapy as a function of HER2 and TOP2A status. J Clin Oncol Off J Am Soc Clin Oncol. 20 août 2009;27(24):3881-6.

26. Pritchard KI. Are HER2 and TOP2A useful as prognostic or predictive biomarkers for anthracyclinebased adjuvant chemotherapy for breast cancer? J Clin Oncol Off J Am Soc Clin Oncol. 20 août 2009;27(24):3875-6.

27. Jm B, Af M, Ja D, C M, S J, Cj T, et al.Predictive markers of anthracycline benefit: a prospectively planned analysis of the UK National Epirubicin Adjuvant Trial (NEAT/BR9601). Lancet Oncol. 13 janv 2010;11(3):266-74.

28. Toffoli G, Corona G, Basso B, Boiocchi M. Pharmacokinetic optimisation of treatment with oral etoposide.Clin Pharmacokinet. 2004;43(7):441-66.

29. Eisenhauer EA, Therasse P, Bogaerts J, Schwartz LH, Sargent D, Ford R, et al.New response evaluation criteria in solid tumours: revised RECIST guideline (version 1.1). Eur J Cancer Oxf Engl 1990. janv 2009;45(2):228-47.

30. Chin S-F, Santonja A, Grzelak M, Ahn S, Sammut S-J, Clifford H, et al. Shallow whole genome sequencing for robust copy number profiling of formalin-fixed paraffin-embedded breast cancers. Exp Mol Pathol. juin 2018;104(3):161-9.

31. Parker H, Carr L, Syeda S, Bryant D, Strefford JC. Characterization of Somatically-Acquired Copy Number Alterations in Chronic Lymphocytic Leukaemia Using Shallow Whole Genome Sequencing. Methods Mol Biol Clifton NJ. 2019;1881:327-53.

32. Raman L, Dheedene A, De Smet M, Van Dorpe J, Menten B. WisecondorX: improved copy number detection for routine shallow whole-genome sequencing. Nucleic Acids Res. 28 févr 2019;47(4):1605-14.

33. Eeckhoutte A, Houy A, Manié E, Reverdy M, Bièche I, Marangoni E, et al. ShallowHRD: detection of homologous recombination deficiency from shallow whole genome sequencing. Bioinforma Oxf Engl. 1 juin 2020;36(12):3888-9.

34. Scheinin I, Sie D, Bengtsson H, van deWiel MA, Olshen AB, vanThuijl HF, et al. DNA copy number analysis of fresh and formalin-fixed specimens by shallow whole-genome sequencing with 
identification and exclusion of problematic regions in the genome assembly. Genome Res. déc 2014;24(12):2022-32.

35. Schemper M, Smith TL. A note on quantifying follow-up in studies of failure time. Control Clin Trials. août 1996;17(4):343-6.

36. R: The R Project for Statistical Computing [Internet].[cité 17 févr 2021]. Disponible sur: https://www.rproject.org/

37. Munzone E, Colleoni M. Clinical overview of metronomic chemotherapy in breast cancer. Nat Rev Clin Oncol. nov 2015;12(11):631-44.

38. Cardoso F, Colleoni M, Leo A, Francia G, Gennari A, Gligorov J, et al. Oral chemotherapy in advanced breast cancer: expert perspectives on its role in clinical practice. Cancer Treat Commun. 1 juin 2016;6:S1-10.

39. Atienza DM, Vogel CL, Trock B, Swain SM. Phase II study of oral etoposide for patients with advanced breast cancer. Cancer. 15 déc 1995;76(12):2485-90.

40. Nesković-Konstantinović ZB, Bosnjak SM, Radulović SS, Mitrović LB. Daily oral etoposide in metastatic breast cancer. Anticancer Drugs. juill 1996;7(5):543-7.

41. Martín M, Lluch A, Casado A, Santabárbara P, Adrover E, Valverde JJ, et al. Clinical activity of chronic oral etoposide in previously treated metastatic breast cancer. J Clin Oncol Off J Am Soc Clin Oncol. mai 1994;12(5):986-91.

42. Saphner T, Weller EA, Tormey DC, Pandya KJ, Falkson Cl, Stewart J, et al. 21-day oral etoposide for metastatic breast cancer: a phase II study and review of the literature.Am $\mathrm{J}$ Clin Oncol. juin 2000;23(3):258-62.

43. Palombo H, Estapé J, Viñolas N, Grau JJ, Mañé JM, Daniels $M$, et al.Chronic oral etoposide in advanced breast cancer. Cancer Chemother Pharmacol. 1994;33(6):527-9.

44. Valabrega G, Berrino G, Milani A, Aglietta M, Montemurro F. A retrospective analysis of the activity and safety of oral Etoposide in heavily pretreated metastatic breast cancer patients. Breast J. juin 2015;21(3):241-5.

45. Giannone G, Milani A, Ghisoni E, Genta S, Mittica G, Montemurro F, et al. Oral etoposide in heavily pretreated metastatic breast cancer: A retrospective series. Breast Edinb Scotl. avr 2018;38:160-4.

46. Yuan P, Di L, Zhang X, Yan M, Wan D, Li L, et al. Efficacy of Oral Etoposide in Pretreated Metastatic Breast Cancer.Medicine (Baltimore) [Internet]. 1 mai 2015 [cité 20 févr 2021];94(17). Disponible sur: https://www.ncbi.nlm.nih.gov/pmc/articles/PMC4603047/

47. Voutsadakis IA. A Systematic Review and Pooled Analysis of Studies of Oral Etoposide in Metastatic Breast Cancer. Eur J Breast Health. 1 janv 2018;14(1):10-6.

48. Bartsch R, Wenzel C, Gampenrieder SP, Pluschnig U, Altorjai G, Rudas M, et al. Trastuzumab and gemcitabine as salvage therapy in heavily pre-treated patients with metastatic breast cancer. Cancer Chemother Pharmacol. oct 2008;62(5):903-10. 
49. Yardley DA, Burris HA, Hanson S, Greco FA, Spigel DR, Barton J, et al. Weekly gemcitabine and trastuzumab in the treatment of patients with HER2-overexpressing metastatic breast cancer. Clin Breast Cancer. août 2009;9(3):178-83.

50. Burstein HJ, Keshaviah A, Baron AD, Hart RD, Lambert-Falls R, Marcom PK, et al. Trastuzumab plus vinorelbine or taxane chemotherapy for HER2-overexpressing metastatic breast cancer: the trastuzumab and vinorelbine or taxane study. Cancer. 1 sept 2007;110(5):965-72.

51. Farhat F, Kattan JG, Ghosn M. Oral vinorelbine in combination with trastuzumab as a first-line therapy of metastatic or locally advanced HER2-positive breast cancer. Cancer Chemother Pharmacol. 2016;77(5):1069-77.

52. Blancas I, Aguirre E, Morales S, Gonzálvez ML, Servitja S, Díaz N, et al. Real-world data on the efficacy and safety of weekly oral vinorelbine in breast cancer patients previously treated with anthracycline or taxane-based regimens. Clin Transl Oncol Off Publ Fed Span Oncol Soc Natl Cancer Inst Mex. avr 2019;21(4):459-66.

53. Lee YR, Huh SJ, Lee DH, Yoon HH, Seol Y-M, Choi Y-J, et al. Phase II Study of Vinorelbine Plus Trastuzumab in HER2 Overexpressing Metastatic Breast Cancer Pretreated with Anthracyclines and Taxanes. J Breast Cancer. juin 2011;14(2):140-6.

54. Pernas S, Tolaney SM. HER2-positive breast cancer: new therapeutic frontiers and overcoming resistance. Ther Adv Med Oncol. 2019;11:1758835919833519.

55. Modi S, Saura C, Yamashita T, Park YH, Kim S-B, Tamura K, et al. Trastuzumab Deruxtecan in Previously Treated HER2-Positive Breast Cancer. N Engl J Med. 13 févr 2020;382(7):610-21.

56. Trastuzumab Deruxtecan Data Impresses at ESMO. Cancer Discov. nov 2021;11(11):2664-5.

57. Murthy RK, Loi S, Okines A, Paplomata E, Hamilton E, Hurvitz SA, et al. Tucatinib, Trastuzumab, and Capecitabine for HER2-Positive Metastatic Breast Cancer. N Engl J Med. 13 2020;382(7):597-609.

58. Seoane JA, Kirkland JG, Caswell-Jin JL, Crabtree GR, Curtis C. Chromatin regulators mediate anthracycline sensitivity in breast cancer. Nat Med. 2019;25(11):1721-7.

\section{Figures}




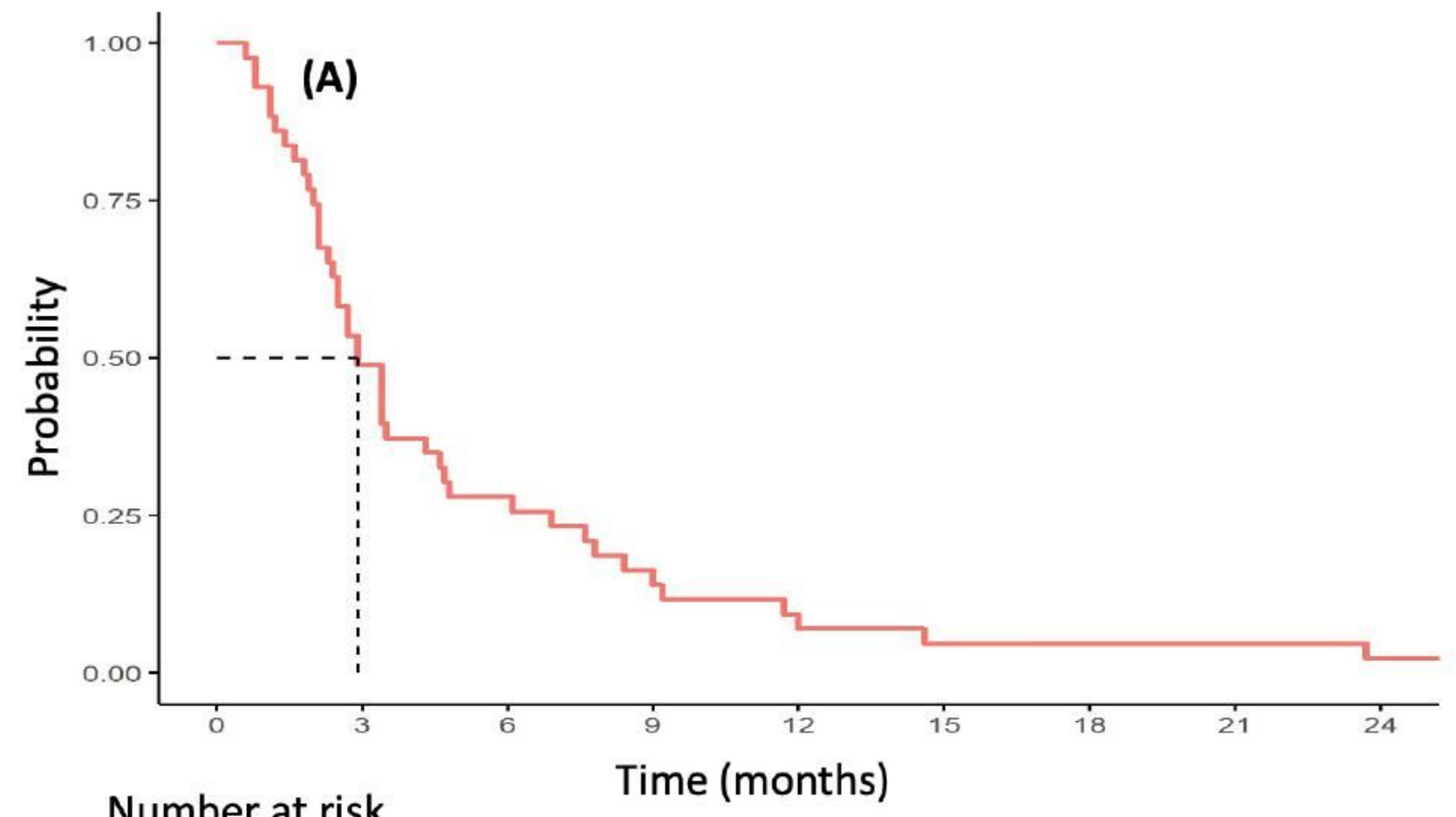

Number at risk

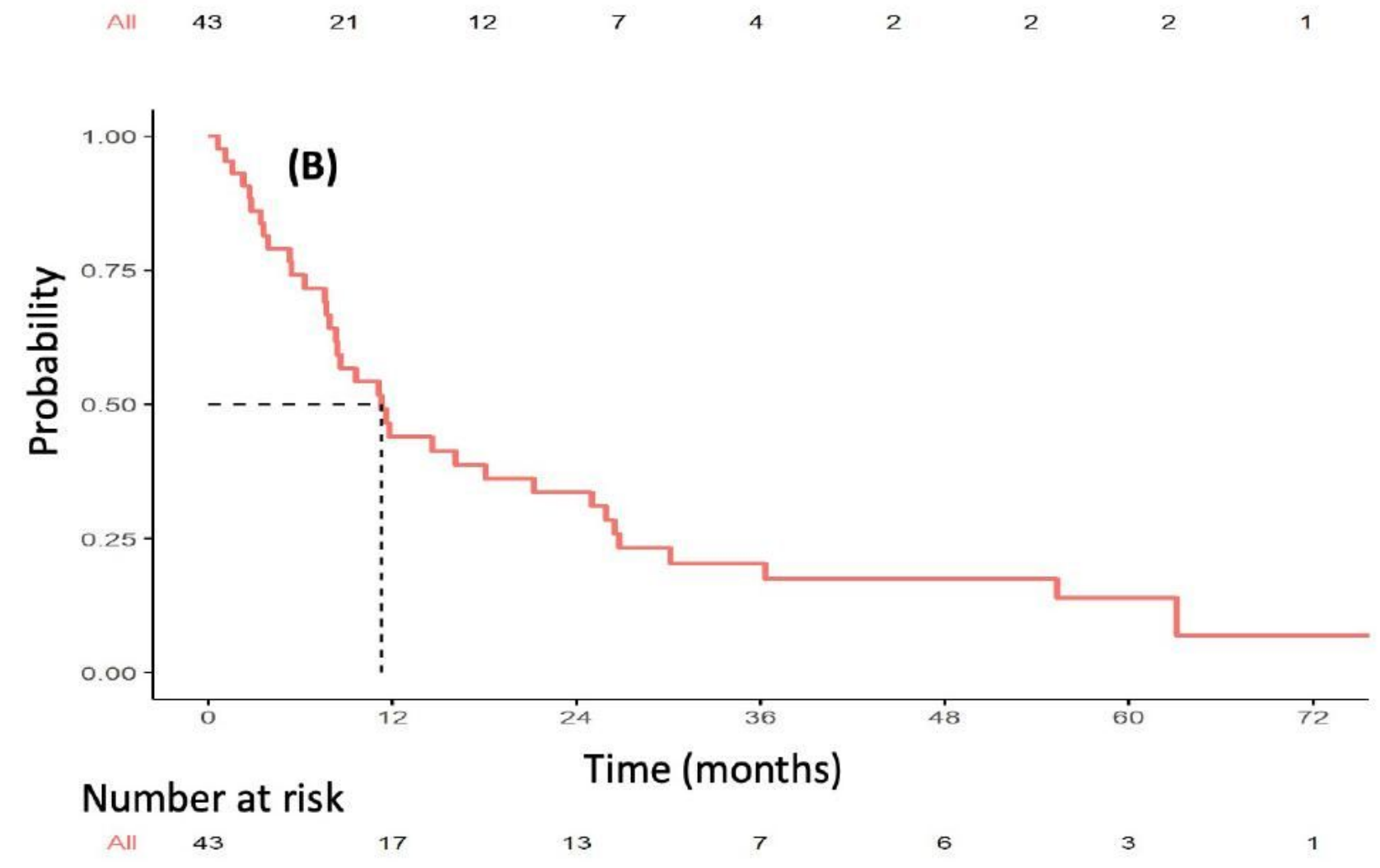

Figure 1

Kaplan-Meier Estimates of Progression-Free Survival (A), Overall Survival (B) in patients treated with VP16-T 


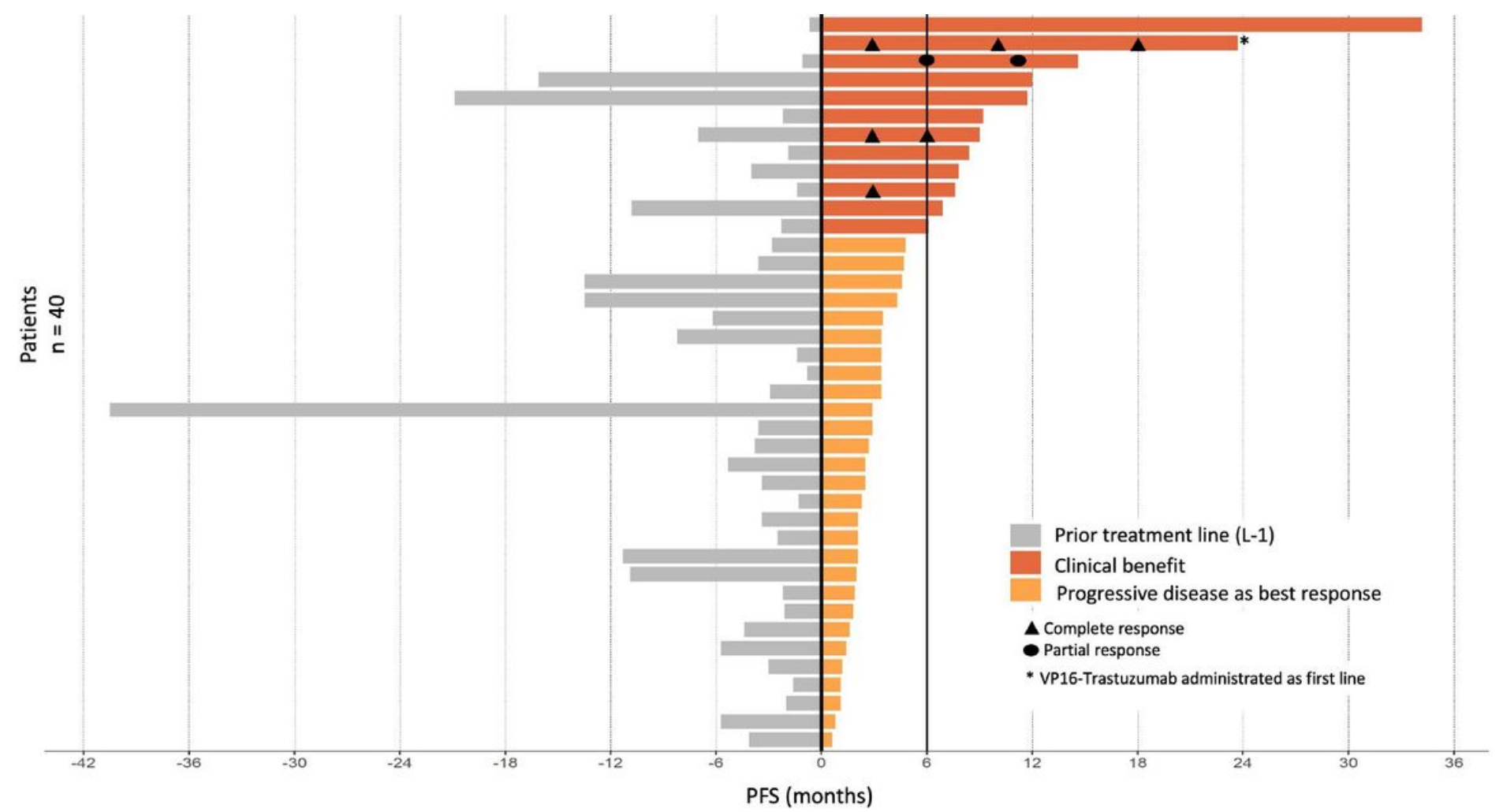

Figure 2

PFS by patient, under prior treatment line and under VP16-T

Clinical benefit is defined by either an objective tumor response ( $N=4$ patients) and/or a PFS under VP16T longer than 6 months ( $\mathrm{N}=8$ patients). 


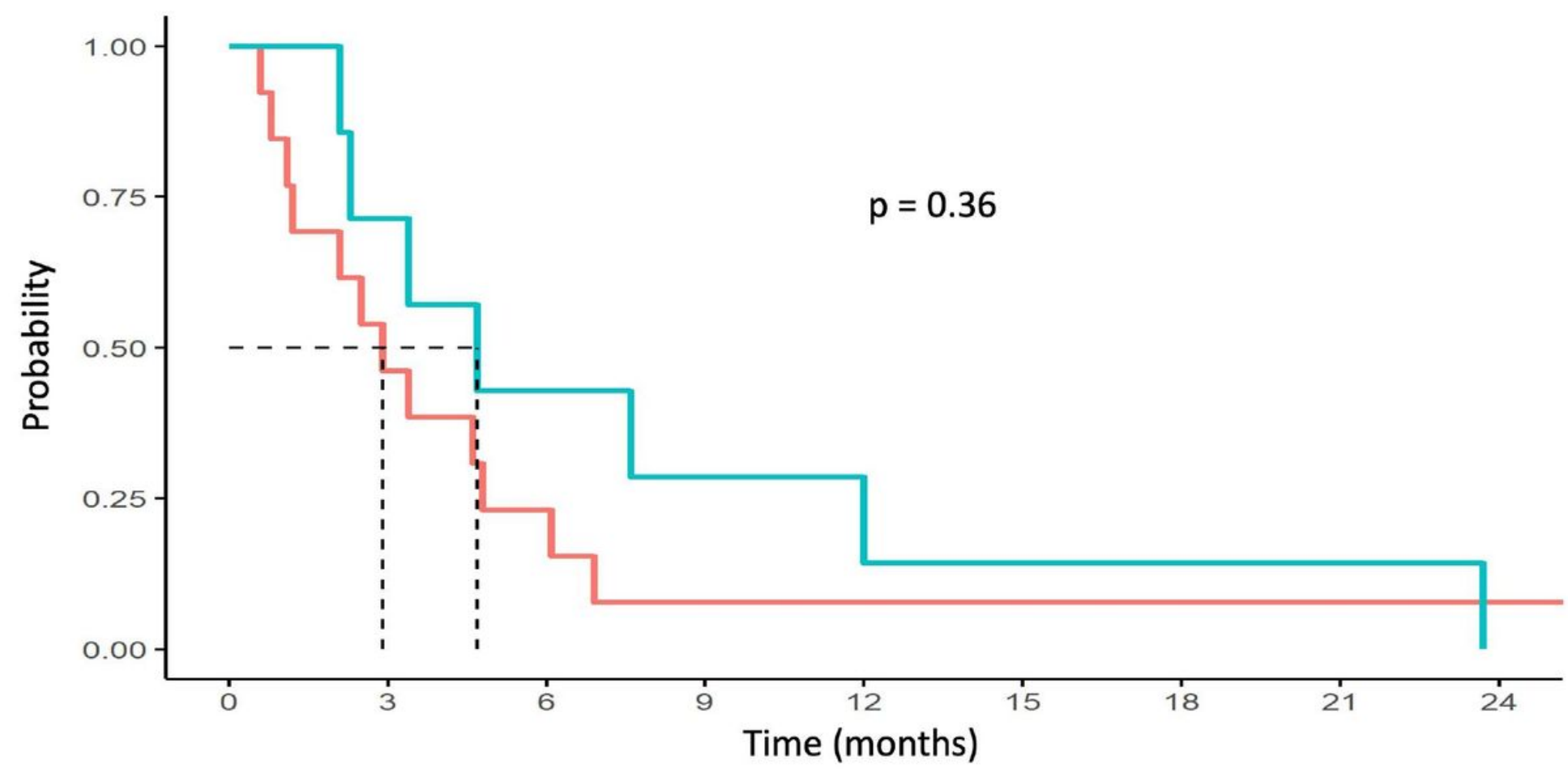

Number at risk

$\begin{array}{cccccccccc}\text { no } & 13 & 6 & 3 & 1 & 1 & 1 & 1 & 1 & 1 \\ \text { yes } & 7 & 5 & 3 & 2 & 2 & 1 & 1 & 1 & 0\end{array}$

Figure 3

PFS depending of TOP2A/ERBB2 co-amplification status

\section{Supplementary Files}

This is a list of supplementary files associated with this preprint. Click to download.

- Supplementaryfile1.docx

- Supplementaryfile2.docx

- Supplementaryfile3.docx 